\title{
Design of Effective 33/11 kV Injection Substations Using Appropriate Standards
}

\author{
Yinka Oyeleye ${ }^{\mathrm{a},}{ }^{*}$, Dare Adeniran ${ }^{\mathrm{b}}$. and Emmanuel Itodo ${ }^{\mathrm{a}}$ \\ ${ }^{a}$ Department of Electrical and Electronics Engineering, School of Engineering and \\ Engineering Technology, Federal University of Technology Akure Nigeria \\ ${ }^{b}$ Department of Electrical and Electronics Engineering, Faculty of Engineering, Federal \\ Polytechnic Ile-Oluji, Nigeria
}

\begin{abstract}
This research focuses on the design of an effective 33/11 kV modelled injection substation that conforms to an appropriate standard for equipment protection, the safety of personnel and power quality compliance. This is to provide a solution to one of the major problems industries in Nigeria faces due to sudden voltage fluctuations in the power system which results in damages to equipment and thus outage of power supply and damages to substation equipment. The methodology involved designing an effective 33/11 kV injection substation and associated distributive substation elements using international codes and applicable algorithms. 60\% loading of transformer and additional 1.25 factor of future expansion (F.E) were considered too. The results showed that a $7.5 \mathrm{MVA}$ injection transformer was designed to operate at $60 \%$. Also, the results revealed that the injection substation would feed 15 numbers of $500 \mathrm{kVA}$ distributive transformers. Each distribution substation was sized in accordance with the 7.5MVA injection transformer philosophy in this work. This research concludes that the injection substation must be loaded at $60 \%$ with an additional 1.25 F.E. in order to increase the transformer life span, and the 7.5MVA injection substation can crater for $15 n o s$ of $500 \mathrm{kVA}$ distribution transformers in this research. Each substation will reliably and effectively carry the expected load demand. This research recommends that injection substations should be designed for areas with high energy requirements for reliable power quality. It recommends that substations should conform to $60 \%$ loading at the initial years of usage and that the substation design should conform to appropriate standards used in this work.
\end{abstract}

Keywords: Substation, Design-codes, Transformer, Substation-elements, Power-quality.

\section{Introduction}

Electric power systems are daily exposed to service interruption mainly due to faults and human accidental interference. A power system fault is defined as any failure which interferes with the normal current flow [1]. However, one of the major problems industries in Nigeria face is to counter the sudden voltage fluctuations in the system which results in the deterioration of power quality and damages to equipment which invariably leads to an outage of power supply. The consequences of power incidents show that industrial and digital firms are losing revenue per year due to power interruptions $[1,2]$. The

\footnotetext{
* Corresponding author.

E-mail address: mooyeleye@futa.edu.ng

Manuscript History:

Received 8 July, 2021, Revised 26 September, 2021, Accepted 26 September, 2021, Published 31 October, 2021

Copyright (C) 2021 UNIMAS Publisher. This is an open access article under the CC BY-NC-SA 4.0 license.

https://doi.org/10.33736/jaspe.3625.2021
}

e-ISSN: 2289-7771

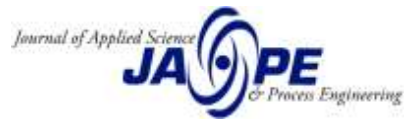


cost to replace equipment damaged because of voltage spikes is very high as this results in a reduction in production. Electricity supply is very important as it affects all spheres of life. Power supply to consumers must be reliable, adequate and of acceptable quality at a minimum cost. This is not easily achievable as the reliability and adequacy of supply are being truncated by incessant faults along the line which reduces the efficiency of the system [3]. However, studies had been carried out on ways to increase power system stability by eliminating fault from the system with a view to determine appropriate protection schemes for the distribution network in order to improve power reliability $[1,2]$. According to [4], evaluation of protection scheme for substation equipment reflected that adequate protection should be reinforced with screening method of protection using lightning arrester in order to mitigate the disastrous effects of a lightning strike. Also, substation periodic earthing inspection should be evaluated to ensure that the earthing system for such a station conformed to the standard to ensure the protection of the equipment and safety of personnel. However, damages to substation equipment were due to the poor protection scheme of the substation [5]. With good design, equipment damages could be eliminated in a substation. Also, with a good substation design, power quality at the receiving would be improved. Therefore, this research aims to design a $33 / 11 \mathrm{kV}$ injection substation that conforms to the national electric code in order to ensure equipment protection, the safety of the personnel and improves the power quality at the receiving end. This work is to serve as a model for injection substation designs, academically and professionally, most especially in Nigeria where power outage due to poor substation design is a problem. This paper does not consider the design of measuring devices. It will be a subject of further research.

\section{Literature Review}

The frequent outages in the distribution network in Nigeria are due to the occurrence of a fault on the power supply networks. However, overloading of the substation elements is a major cause of outage which leads to load shedding [1]. In order to overcome the occurrence of a fault and associated load shedding, there is a need to size the substation elements in accordance with appropriate and applicable standards used in this work such as the National Electric Code (NEC), British International Standard (BIS), Nigeria Electricity Supply and Installation Standards (NESIS), the National Electrical Manufacturer (NEMA) Standard and the International Electrochemical Commission (IEC). This research contributes to knowledge by using appropriate standards to size substation elements and appropriate loading of the distribution transformer since the percentage loading of transformer determines the lifespan of the transformer. This research reviews that in order to increase the life span of a transformer, the percentage loading must be considered.

\subsection{Substation}

An electrical power system is subdivided into generation, transmission and distribution sections. The subsystem that generates electrical energy is called the generation subsystem or generating plants (stations). In Nigeria, electrical power is classified based on the voltage level which are generation, transmission and distribution. However, the distribution network starts at the injection substation where power is delivered by overhead transmission lines and stepped down by a power transformer from 33 $\mathrm{kV}$ to $11 \mathrm{kV}$ [3]. The main component of every power station is the power transformer which is the most expensive equipment in any substation [5]. Therefore, all necessary precautions must be put in place in order to protect the transformer from fault. The substation also helps to improve the power quality from the sending end to the receiving end. 


\subsection{Substation Elements}

These are elements that make up an electrical substation which also embrace transformers protection, control and safety of personnel working within the substation. The substation elements must be protected for equipment and personnel safety within the substation. The elements must be able to detect the normal and abnormal operating conditions of the substation. The substation elements must be of high sensitivity, precision and accuracy $[6,7]$.

\subsubsection{Isolator}

The safety of personnel working in the substation is paramount. There is a need to open a circuit when an engineer is working in any substation. An isolator is used to open a circuit physically for the safety of personnel when working in the substation. This serves as the second protection for the personnel in case the circuit breaker malfunction to avoid the flow of current to the working personnel. An isolator is also used for sectionalizing power lines during fault location. Isolators are always opened on no-load conditions $[8,9]$.

\subsubsection{High Tension Fuse (HTF)}

The high tension fuse is used to protect the transformer against overcurrent fault. The primary current of the transformer is used to size the high tension fuse. However, according to [10] it should be rated 3 times maximum the primary current of the transformer. However, [7] used 1.25 factor in the design of $11 / 0.415 \mathrm{kV}$. The fuse must operate effectively when there is a fault to isolate the faulty circuit.

\subsubsection{Circuit Breaker}

The circuit breaker is a device that operates under normal and abnormal operating conditions in the power circuit. During abnormal conditions, the circuit will open automatically when there is a fault and isolate the fault in order to protect the power system equipment. To allow any personnel to work on faulty equipment in the substation, the circuit breaker must be open to ensure the safety of the personnel $[7,8]$.

\subsubsection{Cable (Conductor)}

Copper $(\mathrm{Cu})$ and Aluminum $(\mathrm{Al})$ are the major metallic materials that conform to the electrical property conductance. They allow the flow of electric charge in them. Also, they are used to transfer electrical energy from one point to another. However, Al conductors are often used in the overhead power system because they are cheaper and lighter in weight. The electrical conductivity of $\mathrm{Cu}$ is greater than that of $\mathrm{Al}$, notwithstanding $\mathrm{Al}$ conductor is still often used than $\mathrm{Cu}$ due to its lighter weight. The selection of conductors depends mainly on the loads rating, environmental conditions and place of installation. Also, the ampacity of electrical components depends on the current ratings and corresponding voltage drop. $[7,11]$.

\subsubsection{Armoured Cable}

The insulation of cable suffered deterioration called local electrical discharge in the late eighteenth century. However, this was overcome by the designer of oil-filled cable Emmanuli in the early nineteenth century. In the mid-nineteenth century, Polyvinyl Chloride (PVC) became popularly known but was hindered by high temperatures and created poisonous acidic gases. Armoured cable was

e-ISSN: 2289-7771

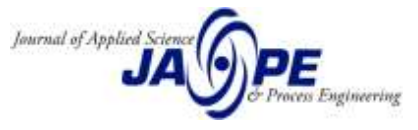


built with an armour of $\mathrm{Al}$ wire or Steel wire. It was used to protect against mechanical damages, corrosions and water during underground installation [7].

\subsubsection{Control Panel (CP)}

This is a cabinet for electrical components used to control the outgoing and incoming feeders. It can be indoor or outdoor. In this work, it was placed indoors (control room). All associated feeders to the substation were on the panel where the operator was able to take readings at regular intervals and monitor the electrical parameters (current, voltage, frequency) in order to ensure power system stability. Bus Bar was often incorporated [8].

\subsubsection{Lighting Arrester}

Some substation elements are always installed outdoor. As a result of this, they are prone to light surges [2]. Hence, there is a need for protection against light surges which can cause damage to any substation element. In order to avoid damage, there is a need for a lighting arrester. Many arresters are used to ground the surges. However, metal oxide lightning arresters were used in this research due to their superior energy absorption capability, better surge protection, more stable protective characteristics and substantial reduction overvoltage across equipment as compared to other types of arresters $[8,13]$. The design criteria were that it should operate at 1.1 times the rated voltage [10]. The down conductor for discharging current to the ground was sized to $161 \mathrm{~mm}^{2}$ [5].

\subsubsection{Power Transformer}

An electrical machine is used for changing power from one level to another through the electromagnetic induction circuit at constant frequency is termed as a power transformer [7,8]. Transformers can either step down or step up the voltage levels of a system for distribution, transmission and generation purposes. The continuous loading of transformer for high efficiency is $50 \%[13,14,15$, 16]. For un-repaired transformer $50-60 \%$ variation is acceptable [16]. It is good to note that the loading of the transformer is directly proportional to its losses ( $1.9 \%$ max). The overloading of the transformer is also directly proportional to its previous loading, which is also proportional to oil temperature at the initial overloading [16]. In this research, initial $60 \%$ efficiency was considered since the transformer in this work was an unrepaired one.

\subsubsection{Earthing Network}

Earthing network is a necessity for the safety of life and property. The metallic part of the electrical devices and installation are connected to form the earthing network. The grounding or earthing values should not be greater than $10 \mathrm{Ohms}[17,18,19,20]$. Earth network is embedded in the ground and electrically connected to it are earthing cables. The earthing system comprises three main components which are the ground conductor, a connection between the ground conductor and ground electrode and the ground electrode $[21,22]$.

\subsubsection{Design Considerations}

Some factors need to be considered when designing a substation. The following factors were put into consideration nearest to an existing high voltage supply $(33 \mathrm{kV})$ incorporation of the future expansion of load (1.25 factor), reliability of elements used, effective grounding, the ability of a protective element to trip when desired and longevity of the transformer. 


\section{Methodology}

Determining and sizing of an appropriate transformer including associated substation elements that would correspond to the injection substation. This philosophy was to produce a typical model of injection substations and their associated distributive substations.

\subsection{Design Considerations}

Design considerations were essential for safety operational design and maintenance. These included (1) being nearest to the existing high voltage supply, (2) having an adequate sizing of tripping device, (3) $60 \%$ loading of the transformer, (4) 1.25 future expansion, (5) consistency of substation elements, and (6) earth resistance code compliance.

\subsection{Design Codes (Standards)}

The applicable design code of substation elements is shown in Table 1. These codes had been carried out on various projects with success. The successful projects comprised international and local multinational petroleum industries including manufacturing industries and large residential buildings.

Table 1: Design code of substation materials $[5,8,10,17,18,20]$

\begin{tabular}{|c|c|}
\hline Substation element & Code / multiplying factors (NEC) \\
\hline Low tension fuse & 1.25 \\
\hline High tension fuse & $1.25-3.0$ \\
\hline Isolator & 1.25 \\
\hline Circuit breaker / panel/ busbar & 1.25 \\
\hline Load future expansion & 1.25 of the actual load \\
\hline Lighting arrester & 1.1 \\
\hline Ground conductor, $\mathrm{G}_{\mathrm{c}}$ & $G_{c}=\frac{1}{2} *$ Phase curret, $I_{p}$ \\
\hline Lightning down conductor and rod $/ \mathrm{mat}$ & $161 \mathrm{~mm}^{2}$ \\
\hline Earthing value & $10 \Omega \mathrm{Max}^{2}$ \\
\hline Maximum voltage & $33 \pm 5 \%$ \\
\hline
\end{tabular}

\subsection{Sizing of Substation Elements}

Applicable and appropriate codes, guidelines, and formulas were applied to size the substation elements as listed in Table 2. In addition to the expected load data, the equations that were used are stated in Table 2. 
Table 2: Substation Elements Formula

\begin{tabular}{|c|c|c|}
\hline Element & Formula & Unit \\
\hline Transformer sizing & $P=1.732 \mathrm{IV}$ & VA \\
\hline $33 \mathrm{kV}$ high tension (HT) fuse & $I=\frac{P}{1.732 \mathrm{~V}}$ & $\mathrm{~A}$ \\
\hline $11 \mathrm{kV}$ control panel sizing (CPS) of the feeder & CPS $=1.25 \mathrm{x} \mathrm{I}_{\mathrm{s}}$ & $\mathrm{A}$ \\
\hline $33 \mathrm{kV}$ Isolator & $I=\frac{P}{1.732 \mathrm{~V}}$ & $\mathrm{~A}$ \\
\hline $11 \mathrm{kV}$ Voltage Circuit Breaker (VCB) & $I_{r}=1.25 I_{S}$ & $\mathrm{~A}$ \\
\hline Lightning Arrester & LA Value $=10 \% * V_{m}$ & $\mathrm{~V}$ \\
\hline AAC H.V Cable & H.V cable rated $_{2}=1.25 x I_{\mathrm{p} r}$ & $\mathrm{~V}$ \\
\hline Grounding Conductor & $G_{c}=\frac{1}{2} * I_{p}$ & $\mathrm{~mm}^{2}$ \\
\hline
\end{tabular}

Where, I and $\mathrm{V}$ are the rated current and voltage respectively at either primary or secondary side. $\mathrm{P}$ is the power rating of the transformer; $I_{s}$ is the secondary rated current of the panel; 1.25 is the multiplying factor for panel future expansion and also the cable multiplying factor; $\mathrm{V}_{\mathrm{m}}$ is the maximum permissible high voltage; $I_{s}$ is the secondary current; $I_{r}$ is the current carrying capacity of the secondary side of the transformer; $\mathrm{I}_{\mathrm{pr}}$ is the rated primary current.

\section{Results and Analysis}

As per the information in Table 2, the sizing of the substation element was in accordance with the design standards as tabulated in Table 3. A 7.5MVA injection transformer was designed but 4.5MVA was recommended for $60 \%$ loading in order to increase the transformer life span. However, $25 \%$ of future expansion (F.E) was additionally incorporated into 60\% loading. Also, 25\% future expansion was considered in sizing circuit breakers. 1.25 cable multiplier factor was considered in accordance with the code for inductive load code requirement. All injection substation elements were also sized based on appropriate existing standards for substation reliability and maintainability.

For $500 \mathrm{kVA}$ distributive transformers, each was sized in accordance with the 7.5MVA injection transformer philosophy of $60 \%$ loading. This implied that the $500 \mathrm{kVA}$ distributive transformers would be loaded at $60 \%(300 \mathrm{kVA})$ to increase the transformer life span and $75 \%(375 \mathrm{kVA})$ with future expansion (FE). The provision of FE for the transformer would still increase the transformer life span since the initial loading and use of the distributive transformers would not be at once with reference to the year of usage. Figure 1 shows a single line modelled diagram of effective $33 / 11 \mathrm{kV}$ injection substations using appropriate standards. 
Table 3: Result of Injection Substation Elements Sizing

\begin{tabular}{|c|c|c|c|c|}
\hline \multirow{2}{*}{ Equipment } & \multicolumn{3}{|c|}{$\begin{array}{l}\text { Design } \\
60 \%\end{array}$} & \multirow[t]{2}{*}{ Recommendation } \\
\hline & kVA & $\mathbf{A}$ & kVA & \\
\hline Power Transformer & 7500 & & 4500 & $7.5 \mathrm{MVA}$ \\
\hline $\begin{array}{l}\text { Distribution } \\
\text { Transformer }\end{array}$ & 500 & & $\begin{array}{c}375 \\
\text { (with } 1.25 \\
\text { FE) }\end{array}$ & 500 \\
\hline $\begin{array}{c}33 \mathrm{kV} \text { High Voltage } \\
\text { Fuse }\end{array}$ & & 131.2 & 78.7 & 78 \\
\hline $33 \mathrm{kV}$ Isolator & & 131.2 & 78.7 & $200 \mathrm{~A}$ \\
\hline $\begin{array}{c}33 \mathrm{kV} \text { Lightning } \\
\text { Arrester }\end{array}$ & & 36.3 & & $36 \mathrm{kV}$ \\
\hline $33 \mathrm{kV}$ Cable & & 131.2 & & $\begin{array}{c}\text { 3nos of } 35 \mathrm{~mm}^{2}, \text { AAC } \\
\text { Cable }\end{array}$ \\
\hline $\begin{array}{l}11 \text { kV H.V Control } \\
\text { Panel CB }\end{array}$ & & 393.7 & 295.2 & $295 \mathrm{~A}$ \\
\hline $11 \mathrm{kV}$ Cable to Panel & & 492.1 & 369.1 & $\begin{array}{c}3 \text { nos of } 95 \mathrm{~mm}^{2} \text { XLPE } \\
\text { Cable }\end{array}$ \\
\hline $\begin{array}{c}500 \text { kVA Primary } \\
\text { Fuse }\end{array}$ & & 26.2 & 19.7 & $\mathrm{SC}, 95 \mathrm{~mm}^{2}$ XLPE Cable \\
\hline $\begin{array}{c}500 \text { kVA Primary } \\
\text { Cable }\end{array}$ & & & 24.6 & $\mathrm{SC}, 95 \mathrm{~mm}^{2}$ XLPE Cable \\
\hline $\begin{array}{l}\text { 7.5MVA Earthing } \\
\text { conductor }\end{array}$ & & & 148 & $\mathrm{SC}, 95 \mathrm{~mm}^{2}$ XLPE Cable \\
\hline $\begin{array}{l}\text { 500KVA Earthing } \\
\text { conductor }\end{array}$ & & & 9.8 & $\mathrm{SC}, 95 \mathrm{~mm}^{2}$ XLPE Cable \\
\hline
\end{tabular}

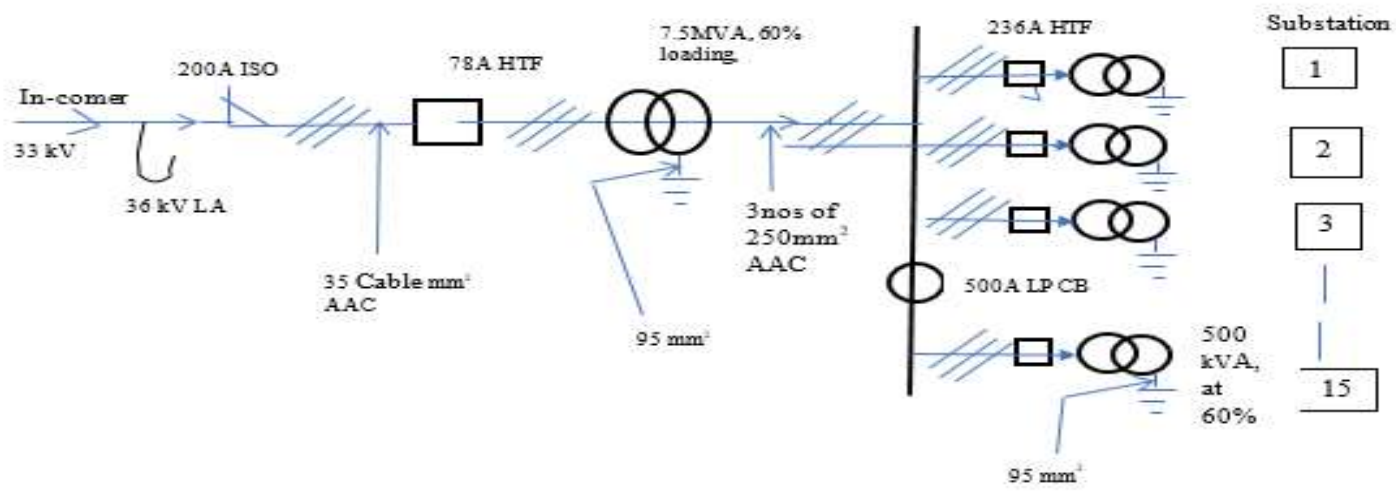

Figure 1: Single line modelled diagram of effective $33 / 11 \mathrm{kV}$ injection substations using appropriate standards 


\section{Conclusions and Recommendations}

An effective $33 / 11 \mathrm{kV}$ injection sub-station was designed using applicable standards. The injection substation is to be loaded at $60 \%$ with 1.25 future expansion. The injection substation craters for $15 \mathrm{nos}$ of $500 \mathrm{kVA}$ distribution transformers at $60 \%$ loading and $75 \%$ loading when 1.25 future expansion is considered. Transformer shorter life span in usage was overcome in this research. Each substation will reliably and effectively carry the expected load demand and meet $25 \%$ future expansion. This research recommends that for a high-quality power supply, injection substations should be designed for areas with high energy consumers for reliable power quality. It also recommends that the substation should conform to $60 \%$ loading at the initial usage to increase the transformer life span. Also, the substation design should conform to applicable standards used in this work.

\section{References}

[1] Obi, P.I., Iloh J.P.I. and Ofoma, C. (2019). Fault analysis of Nnewi power injection substation using phase component method, Umudike Journal of Engineering Technology. Accessed November 2019 www.ujetmouau.com

[2] Melodi, A. O. A., \& Oyeleye, O. M. (2017). Modeling of Lightning Strike Events, and it's Correlational with Power Outages in South-West Coast, Nigeria. International Journal of Electrical and Computer Engineering, 7(6), 3262. DOI: 10.11591/ijece.v7i6.pp3262-3270

[3] Oladimeji, J. A. (2017). Fault Analysis of Injection Substation Using Symmetrical Component Method and Validation of Results Using MATLAB: A Case Study of Mofor Injection Substation, Delta State, Nigeria. International Journal of Advanced Research in Electrical, Electronics and Instrumentation Engineering, 6(4), 1-18.

[4] Oyeleye, M. O. (2019). Evaluation of Lightning Protection Efficacy on Nigerian Installations High Voltage Installations Using Screen and Cone of Protection Methods. European Journal of Engineering and Technology Research, 4(7), 1-10. https://doi.org/10.24018/ejers.2019.4.7.1401.

[5] Oyeleye, M.O. (2017). Evaluation and planning of lightning protection efficacy on Nigerian high voltage installations. Ikorodu $11 \mathrm{kV}-132 \mathrm{kV}$ system as case study. PhD thesis, Federal University of Technology Akure, Nigeria.

[6] Johnson, D. O. (2015). Reliability Evaluation of 11/0.415 kV Substations: A Case Study of Substations in Ede Town. International Journal of Engineering Research \& Technology, 4(09), 127-135. ISSN: 2278-0181

[7] Oyeleye, M.O. (2019). Design of 11/0.415 kV Substation Using Applicable International Codes, Journal of Multidisciplinary Engineering Science Studies (JMESS), 5, 2782-2789.

[8] Nawaz, M. S (2016). Design and Construction of 33/11 kV Line and Substation. International Research Journal of Engineering and Technology (IRJET), 3, 2395 -0056.

[9] Gupta, J. B. (2010). A course in Electrical Installation Estimating and Costing $8^{\text {th }}$ edition. Publisher S.K. Kataria and Sons.

[10] National Electric Code, NEC. International Series, 2005, 711

[11] ABB, XPLE cable system users guide, 2005, 31.

[12] Weedy, B. M., Cory, B. J., Jenkins, N., Ekanayake, J. B., \& Strbac, G. (2012). Electric power systems. John Wiley \& Sons. ISBN: 9780470682685

[13] Technical Report, Guide for Determining Energy Efficiency for Distribution Transformers, NEMA Standards Publication TP 1-2002.

[14] Bureau of Energy Efficiency (India). Determination Analysis of Standards and Labeling Program for Distribution Transformers, 2003.

[15] National Appliance and Equipment Energy Efficiency Program - Australia. Minimum energy performance standards distribution transformers. 2001. 
[16] Zenatix. (2015). Transformer Efficiency Effect of Loading. 7. (Retrieved: zenatix.com/transformerefficiency-effect).

[17] Nigeria Electricity Supply and Installation Standards (NESIS) Regulations. (2015), 280.

[18] British standard. Code of Practice for Protection of Structures Against Lightning, 2005, 112.

[19] International Electrotechnical Committee. (2006). Protection of structures against lightning-Part 1: General principles. IEC 61024-1.

[20] Oyeleye, M. O. (2019). Evaluation of substation's transformer earthing system, feeder panel and lightning grounding: case study of a university in Nigeria. Evaluation, 5(9), 2805-10. ISSN: 2458-925X

[21] Gupta, J. B. (2009). A course in Electrical Power. SK Kataria and Sons.

[22] Gomes, C., Ab Kadir, M. Z. A., Kottachchi, C. L., \& Lim, S. C. (2014). Industrial wastes and natural substances for improving electrical earthing systems. 21(2), 39-47. DOI: 10.6329/CIEE.2014.2.01 